\title{
Basal Cell Carcinoma with Spontaneous Regression: A Case Report and Immunohistochemical Study
}

\author{
Taku Fujimura Aya Kakizaki Yumi Kambayashi \\ Setsuya Aiba
}

Department of Dermatology, Tohoku University Graduate School of Medicine, Sendai, Japan

\section{Key Words}

Basal cell carcinoma - Spontaneous regression - Tumor-infiltrating lymphocytes

\begin{abstract}
Spontaneous regression of basal cell carcinoma (BCC) is rare, and characterized by various tumor-infiltrating lymphocytes (TILs) in the tumor. A previous report suggested that these infiltrated lymphocytes consist of type 1 helper T cells, but no detailed phenotypical analysis of other TILs has been demonstrated yet. In this report, we describe an 84-year-old Japanese patient with spontaneous regression of BCC. In the present case, we investigated the immunohistochemical profiles of TILs, not only focusing on the cytotoxic T cells, but the profiles of immunosuppressive cells, such as regulatory $T$ cells and tumor-associated macrophages. Our present study sheds light on the immunological mechanisms of tumor rejection in human BCC.
\end{abstract}

\section{Introduction}

Spontaneous regression of cutaneous tumors has been documented previously, but reports of partial spontaneous regression of basal cell carcinoma (BCC) are rare [1]. A number of factors are known to contribute to the development of BCC. Recently, the role of immunological factors and angiogenic factors in BCC has been investigated, especially focusing on regulatory $\mathrm{T}$ cells (Tregs), immunosuppressive macrophages and matrix metalloproteinase [2-4].

Immunological tolerance of self-antigens is essential for the prevention of autologous reactions and autoimmune diseases. In the peripheral organs, tolerance is 
reinforced by a variety of mechanisms, including a population of Tregs, tumorassociated macrophages (TAMs), myeloid-derived suppressor cells (MDSC), and CD163+ M2 macrophages [5-7]. To evaluate the tumor microenvironment from an immunological point of view, not only assessing the tumor-infiltrating cytotoxic $\mathrm{T}$ cells, such as TIA1+, CD8 ${ }^{+} \mathrm{T}$ cells, but also investigating these immunosuppressive cells is mandatory. In this report, we describe a case of BCC with spontaneous regression and employed immunohistochemical staining to verify the tumor-infiltrating lymphocytes (TILs), with special focus on the profiles of $\mathrm{T}$ cell subsets and tumor-infiltrating macrophages.

\section{Case Report}

An 84-year-old Japanese man visited our outpatient clinic with a ten-year history of an asymptomatic, pigmented nodule on his breast. On his initial visit, physical examination revealed a brown-colored, elastic-hard, well-demarcated nodule with prominent teleangiectasia and erythema on the right breast (fig, 1). The tumor mass was $10 \times 8 \mathrm{~mm}$ in size. Dermatoscopic finding revealed that a prominent large blue-gray ovoid nest and multiple blue-gray globules accompanied by arborizing vessels in the peripheral tumor areas were surrounding the blue-whitish area with dotted or arborizing vessels areas in the center of the tumor (fig. 1b). We excised the tumor with a 3-mm surgical margin from the erythema. Histologically, in the remaining tumor area (fig. $2 \mathrm{a}$ ), a palisaded basophilic tumor island was surrounded by infiltrating lymphocytes. At the center of the tumor, eosinophilic collagen was prominent. In the tumor-regressing area (fig. 2b), numerous melanophages surrounded the eosinophilic collagen and, at this area, lymphocytes were densely infiltrating through the dermis.

From the above data, we diagnosed this patient as having BCC with spontaneous regression. To further investigate the mechanisms of spontaneous regression, we employed immunohistochemical staining, especially focusing on the cytotoxic T cells and immunosuppressive lymphocytes. To evaluate the infiltrating cells in the tumor-regressing area, we performed immunohistochemical stainings in regressive (ig. 3 ) or tumoral areas ( $\underline{\text { fig. } 4}$ ) of BCC for CD3, CD4, CD8, TIA1, Foxp3, CD56, CD68, CD163 and MMP-9, which revealed that these densely infiltrating mononuclear cells were mainly CD3+ (fig. 3a, fig. 4a) and, CD4+ ${ }^{+}$CD8+ (fig. 3b, fig. 4b) and TIA-1+ cells (fig. 3e, fig. 4e). CD68+, $\mathrm{CD} 163^{+}$(fig. 3c, fig. 4c) and MMP-9+ (fig. 3d, fig. 4d) cells were detected mainly around melanophages. Few Foxp3 $3^{\text {high }}$ cells (fig. $3 \mathrm{f}$, fig. $4 \mathrm{f}$ ) and $\mathrm{CD}^{2} 6^{+}$cells were scattered in the $\mathrm{CD}^{+}$area. The number of immunoreactive cells were counted using an ocular grid of $1 \mathrm{~cm}^{2}$ at a magnification of 400 , and summarized in fig. 5 . Staining of infiltrated lymphocytes was examined in more than 5 random, representative fields from each section. Data are expressed as the mean \pm standard deviation for Treg fractions in each skin disorder. For a single comparison of 2 groups, Student's t test was used. The level of significance was set at $\mathrm{p}=0.05$.

\section{Discussion}

With regards to cutaneous tumors, particularly melanoma, there is evidence suggesting that the immune system plays a central role in mediating tumor regression [1]. However, published studies analyzing the mechanisms underlying spontaneous regression in BCCs are few.

Histological criteria for the regression of $\mathrm{BCC}$ were described as follows [1]. The criteria for active regression of BCC include the normal palisaded outline of some tumor islands, accompanied by a lymphocytic infiltrate penetrating and surrounding the tumor nest. The criteria of previous regression were as follows: (i) new eosinophilic collagen in the dermis; (ii) reduction in the skin appendages in the areas of scarring; 
(iii) an increased number of blood vessels; (iv) a variable infiltrate of lymphocytes and plasma cells $[1,8]$. According to these criteria, our present case mainly appeared to represent active regression and, in some parts, contained previous regression patterns.

As we previously reported concerning the profiles of TILs in metastatic malignant melanomas, regressing tumors induce cytotoxic T cells [9]. Concerning BCC, Hunt et al. [1] previously investigated the TILs in regressing and non-regressing BCCs and reported that significant numbers of $\mathrm{CD}^{+}, \mathrm{CD}^{+}$and $\mathrm{CD} 25^{+}$cells were increased in regressing compared with non-regressing tumors. They concluded that cytokines from activated $\mathrm{CD} 4{ }^{+}$cytokine-secreting cells were important in the regression of BCC. Recently, Wong et al. [10] reported that the expression of interferon gamma was significantly elevated in actively regressing BCCs compared with non-regressing BCCs, which suggested the induction of a Th1 cytokine-mediated antitumor immune response. More recently, several reports shed light on the effect of immunosuppressive cells, such as CD163+ M2 macrophages and Tregs on the carcinogenesis of BCC $[2,3]$. Indeed, Tjiu et al. [2] reported that TAMs in BCC are correlated with the depth of invasion, microvessel density, and cyclooxygenase- 2 expression in tumor. About Tregs, Kaporis et al. [3] indicated that CD4+CD25+Foxp3 ${ }^{+}$Tregs surrounded epithelial tumor aggregate in BCC and contributed to maintain a Th2-dominant tumor microenvironment. More recently, we demonstrated the effect of depletion of Tregs on the activation of both $\mathrm{CD}^{+}$and $\mathrm{CD} 8^{+} \mathrm{T}$ cells in murine melanoma models in cooperation with the suppression of MDSC [11]. Indeed, the depletion of Tregs in ret melanoma significantly decreases the expression of B7-H1 on MDSC, which is one of the functional molecules of MDSC for the suppression of T cell proliferation. In aggregate, together with other suppressor cells, such as MDSCs, TAMs and CD163+ M2 macrophages, Tregs promote an immunosuppressive environment in the tumorbearing host $[2,3,5,11]$. In our present case, few Foxp $3^{+}$cells were detected and numerous TIA $1^{+}$cells were infiltrating through the dermis. Immunosuppressive $\mathrm{CD}_{163^{+}} \mathrm{M} 2$ macrophages and MMP-9+ cells were also detected, however, in contrast to cytotoxic T cells, these cells were observed only around the rest of the tumor cells.

In summary, we describe a case of BCC with spontaneous regression. Our present study sheds light on the immunological mechanisms of tumor rejection in human skin cancer and might suggest a possible therapy for such skin tumors by modifying the tumor microenvironment. 

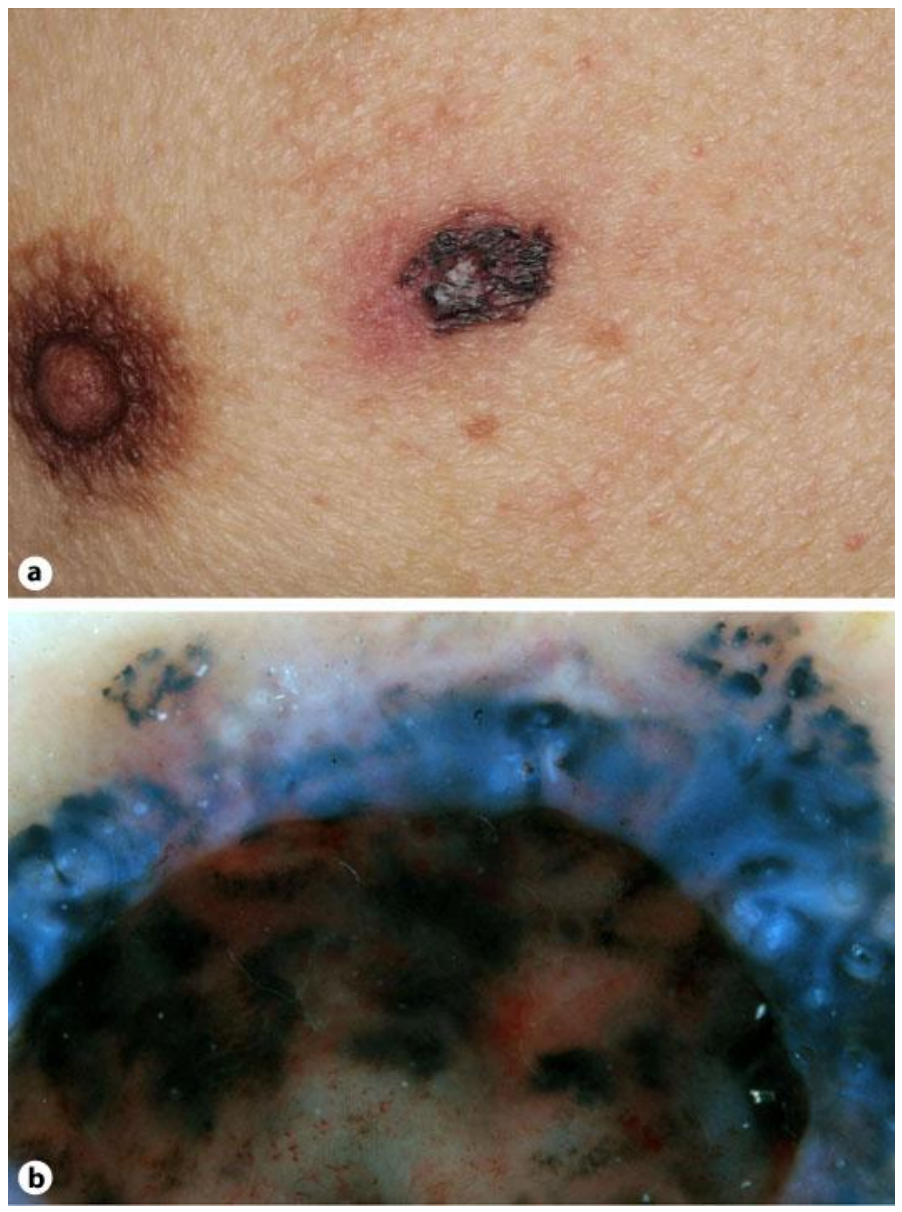

Fig. 1. A brown-colored, elastic-hard, well-demarcated nodule with prominent teleangiectasia and erythema on the right breast (a). A prominent large blue-gray ovoid nest and multiple blue-gray globules accompanied by arborizing vessels in the peripheral tumor areas were surrounding the blue-whitish area with dotted or arborizing vessel areas in the center of the tumor (b). 

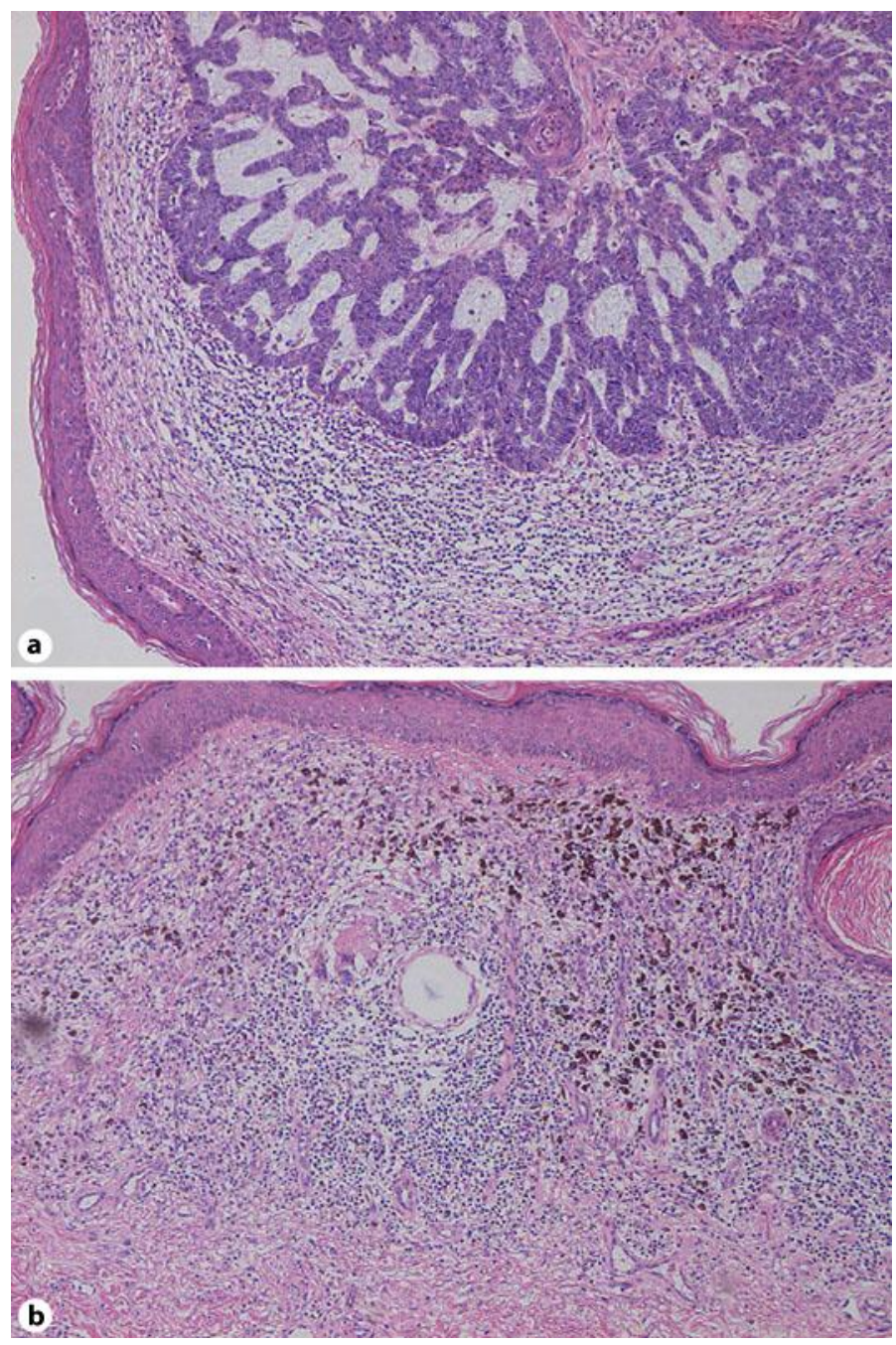

Fig. 2. Palisaded basophilic tumor island was surrounded by infiltrated lymphocytes and, at the center of the tumor, eosinophilic collagen is prominent (a). Numerous melanophages surrounded the eosinophilic collagen and, at this area, lymphocytes were densely infiltrating through the dermis (b). a Peripheral lesion of the tumor. $\mathbf{b}$ Center of the tumor. Original magnification $200 \times$. 

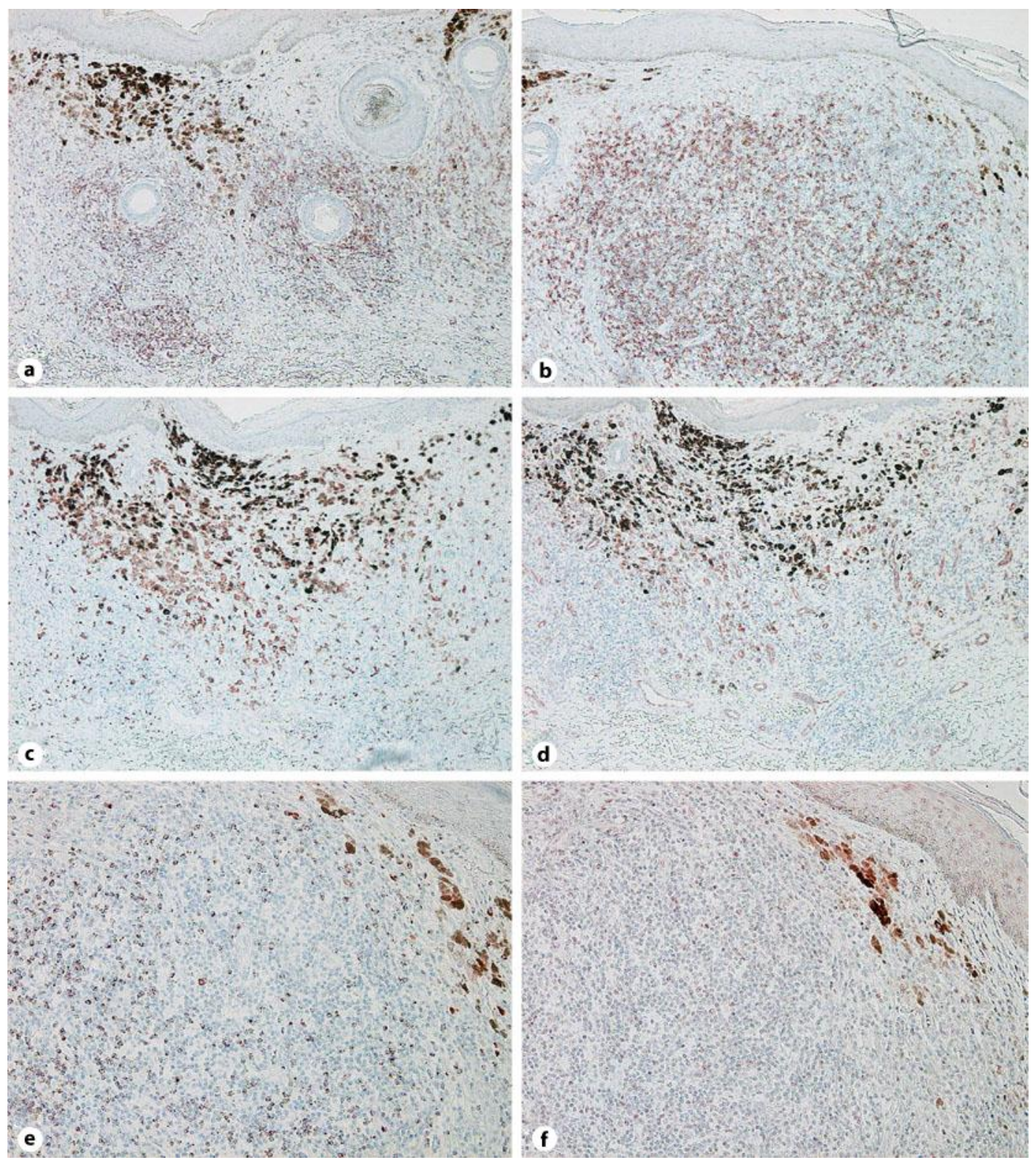

Fig. 3. Regression areas. Paraffin-embedded tissue samples from the patient were stained as follows: the sections were developed with new fuchsin for CD3 (a), CD8 (b), CD163 (c), MMP-9 (d), TIA1 (e), and Foxp3 (f). Original magnification $100 \times(a-d), 200 \times(e, f)$. 

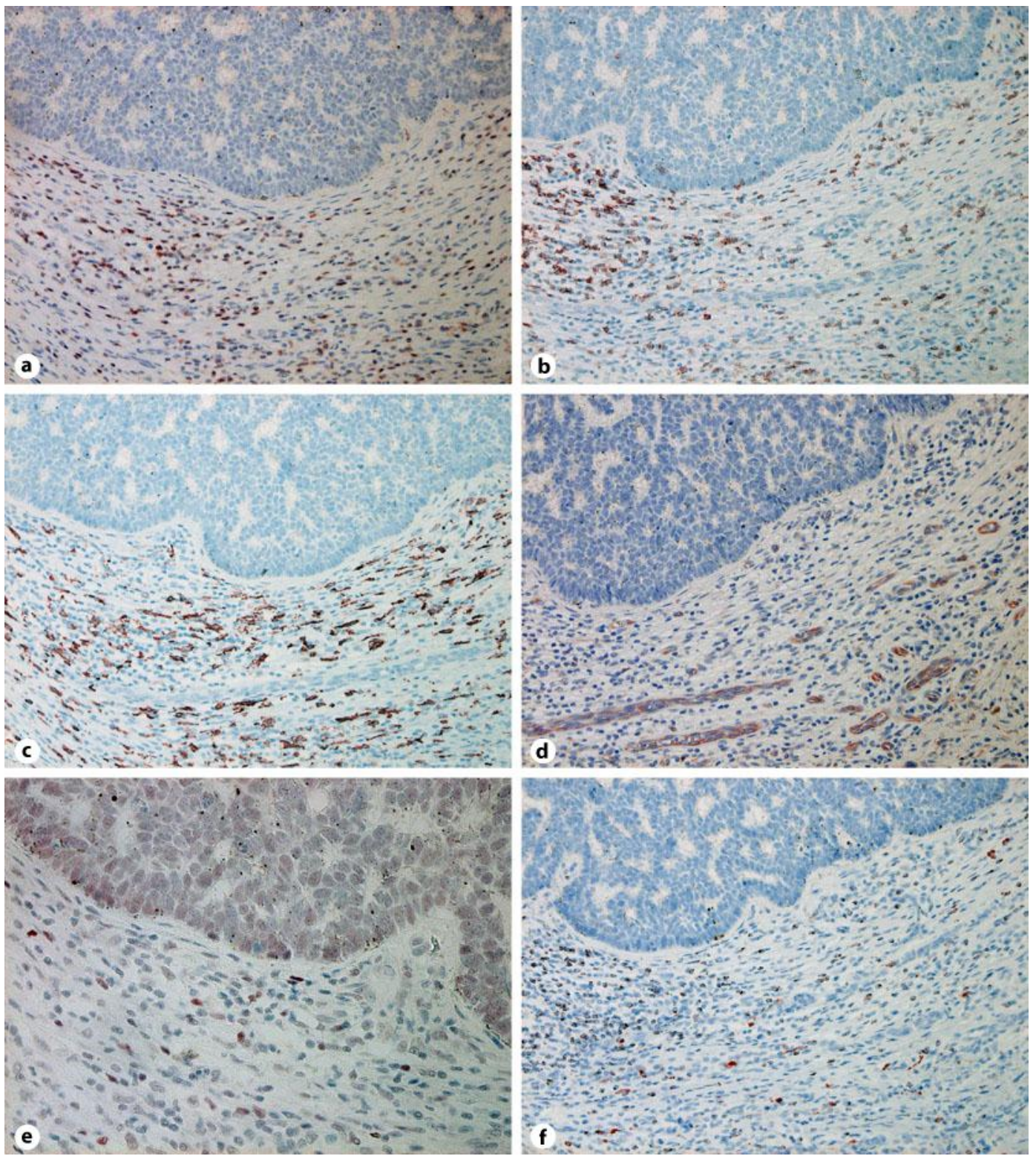

Fig. 4. Tumoral area. Paraffin-embedded tissue samples from the patient were stained as follows: the sections were developed with new fuchsin for CD3 (a), CD8 (b), CD163 (c), MMP-9 (d), TIA1 (e), and Foxp3 (f). Original magnification $200 \times(a-e), 400 \times$ (f). 


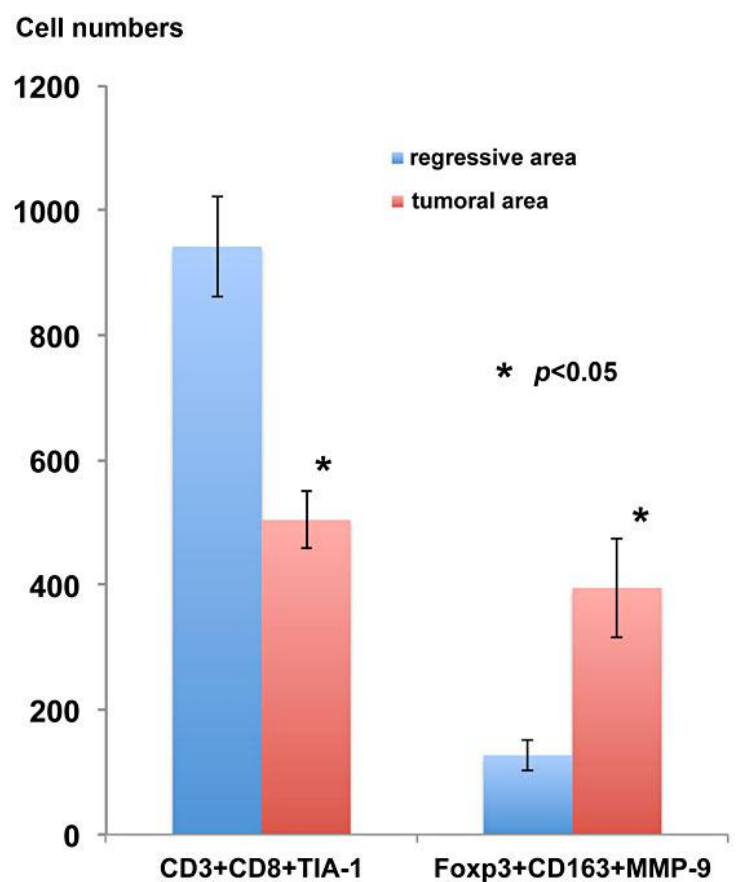

Fig. 5. Summary of the numbers of immunoreactive cells in regressive or tumoral area of BCC. Three representative fields of each section were selected from both the epidermis and the dermis associated with dense dermal lymphoid infiltrate. The number of immunoreactive cells was counted using an ocular grid of $1 \mathrm{~cm}^{2}$ at a magnification of $400 \times$. The data are expressed as the means SD of the numbers in each area. ${ }^{*} \mathrm{p}<0.05$.

\section{References}

1 Hunt MJ, Halliday GM, Weedon D, Cooke BE, Barnetson RS: Regression in basal cell carcinoma: an immunohistochemical analysis. Br J Dermatol 1994;130:1-8.

-2 Tjiu JW, Chen JS, Shun CT, Lin SJ, Liao YH, Chu CY, Tsai TF, Chiu HC, Dai YS, Inoue H, Yang PC, Kuo ML, Jee SH: Tumor-associated macrophage-induced invasion and angiogenesis of human basal cell carcinoma cells by cyclooxygenase-2 induction. J Invest Dermatol 2009;129:1016-1025.

-3 Kaporis HG, Guttman-Yassky E, Lowes MA, Haider AS, Fuentes-Duculan J, Darabi K, Whynot-Ertelt J, Khatcherian A, Cardinale I, Novitskaya I, Krueger JG, Carucci JA: Human basal cell carcinoma is associated with Foxp3+ T cells in a Th2 dominant microenvironment. J Invest Dermatol 2007;127:23912398.

- 4 Monhian N, Jewett BS, Baker SR, Varani J: Matrix metalloproteinase expression in normal skin associated with basal cell carcinoma and in distant skin from the same patients. Arch Facial Plast Surg 2005; 7:238243.

5 Fujimura T, Mahnke K, Enk AH: Myeloid derived suppressor cells and their role in tolerance induction in cancer. J Dermatol Sci 2010;59:1-6.

-6 Sakaguchi S: Naturally arising Foxp3-expressing CD25+CD4+ regulatory T cells in immunological tolerance to self and non-self. Nat Immunol 2005;6:345-352.

-7 Fujimura T, Okuyama R, Ito Y, Aiba S: Profiles of Foxp3+ regulatory T cells in eczematous dermatitis, psoriasis vulgaris and mycosis fungoides. Br J Dermatol 2008;158:1256-1263.

8 Curson C, Weedon D: Spontaneous regression in basal cell carcinoma. J Cutan Pathol 1979;6:432-437.

-9 Fujimura T, Okuyama R, Ohtani T, Ito Y, Haga T, Hashimoto A, Aiba S: Perilesional treatment of metastatic melanoma with interferon-beta. Clin Exp Dermatol 2009;34:793-799.

10 Wong DA, Bishop GA, Lowes MA, Cooke B, Barnetson RStC, Halliday GM: Cytokine profiles in spontaneous regressing basal cell carcinomas. Brit J Dermatol 2000;143:91-98.

11 Fujimura T, Ring S, Umansky V, Mahnke K, Enk AH: Regulatory T cells stimulate B7-H1 expression in myeloid-derived suppressor cells in ret melanomas. J Invest Dermatol 2012;132:1239-1246. 